\title{
Hot deformation behaviors and microstructure evolution in a new PM nickel-base superalloy
}

\author{
Gaofeng Tian ${ }^{a}$, Jinwen Zou ${ }^{b}$, Yu wang ${ }^{c}$, Wuxiang Wang ${ }^{d}$ \\ Beijing Institute of Aeronautical Materials P. O. Box 81-1, Beijing 100095, China \\ a chuntian712@gmail.com, ${ }^{b}$ zoujw03@mails.tsinghua.edu.cn, ${ }^{c}$ wangyu_hit@sohu.com
}

Key words: Nickel base superalloy, microstructure, HIP, hot deformation

\begin{abstract}
The hot deformation behaviors and the effect of flow stress on the microstructure were investigated for the as-HIPed and as-extruded materials in a new PM nickel-base superalloy. Under most test conditions, the as-extruded material exhibits superplastic flow because of grain growth corresponding to work hardening during deformation process, activation energy for deformation of which is $211 \mathrm{~kJ} / \mathrm{mol}$. However, activation energy of deformation for the as-HIPed material is $717 \mathrm{~kJ} / \mathrm{mol}$, because grain size is refined due to dynamic recrystallization, the reason being considered to be associated with the initial microstructure before the deformation. Based on the results of compression tests, two constitutive equations for the two materials were established using the mathematical regression; these will provide the valuable helps for predicting and controlling the deformed microstructure as well as optimizing hot-working process.
\end{abstract}

\section{Introduction}

Powder metallurgy (PM) nickel base superalloy are reaching more attentions for use as turbine discs in gas turbine engines. At the present, the rim temperatures is in excess of $704^{\circ} \mathrm{C}$, and so the higher requirements are put forward for new turbine disc alloys [1-3]. In recent years, new generation nickel-base superalloys, such as René104 (also called ME3) [4], LSHR (Low Solvus, High Refractory alloy) [5], Alloy 10 [6] and N19 (SMO43) [7] are developed; these new alloys are optimized for numerous mechanical and physical properties at the higher temperatures, and also to produce dual microstructure discs (a fine-grain core and a coarse-grain rim), which should have a high potential for optimum performance.

It is more attractive that the microstructure of superalloys is precisely controlled during hot deformation process. There is more interest in the development of techniques, such as predicting microstructure in forgings and numerical simulation of forging process, in order to obtain the excellent mechanical properties of forging components. A number of investigations on hot deformation behavior of nickel base superalloys have been reported in the literature [8-10]. In the present work, the hot deformation characteristics for the as-HIPed and as-extruded materials in a new alloy were investigated using hot compression tests, and the microstructure change and flow behaviors of mentioned materials during deformation were analyzed. The tests of strain rates and temperatures are comparable with the isothermal forging practice for this alloy.

\section{Experimental procedure}

Chemical composition (wt. \%) of the new alloy in this investigation is $20 \mathrm{Co}, 13 \mathrm{Cr}, 3.6 \mathrm{Al}, 3.5 \mathrm{Ti}$, $4.3 \mathrm{~W}, 2.9 \mathrm{Mo}, 1.5 \mathrm{Nb}, 1.5 \mathrm{Ta}, 0.03 \mathrm{~B}, 0.03 \mathrm{C}, 0.05 \mathrm{Zr}, 0.35 \mathrm{Hf}$, and bal. Ni. The powder was produced by argon gas atomization, then sieved to - 250 mesh, canned, HIPed at subsolvus temperature, and extruded to billet at $1100^{\circ} \mathrm{C}$. 
Cylindrical specimens for compression tests having a diameter of $10 \mathrm{~mm}$ and length of $15 \mathrm{~mm}$ were machined from the as-HIPed and as-extruded materials. In this study, compression tests were carried out on a Gleeble-3500 machine in vacuum at $1050^{\circ} \mathrm{C}, 1075^{\circ} \mathrm{C}$ and $1100^{\circ} \mathrm{C}$ using strain rates of $0.0003 \mathrm{~s}^{-1}, 0.003 \mathrm{~s}^{-1}$, and $0.03 \mathrm{~s}^{-1}$.

Optical microscopy (OM) and transmission electron microscopy (TEM) analyses were conducted to observe the microstructure.

\section{Results and discussions}

\section{Microstructure preparing for compression tests}

The microstructures of both as-HIPed and as-extruded materials are shown in Fig. 1. It can be seen from Fig. 1a that recrystallization was only partially completed and fine grained microduplex structures was formed, consisting of a few undeformed powder particles which have retained as-cast dendritic structure (note the arrow in Fig. 1a). To compare with the as-HIPed materials, a uniform fine-grained $(\sim 5 \mu \mathrm{m})$ structure was obtained after extrusion (Fig. 1b). Residual dendritic structures are almost not observed. Primary $\gamma^{\prime}$ phases distribute at grain boundaries as a bright particles, while carbide particles are dark.
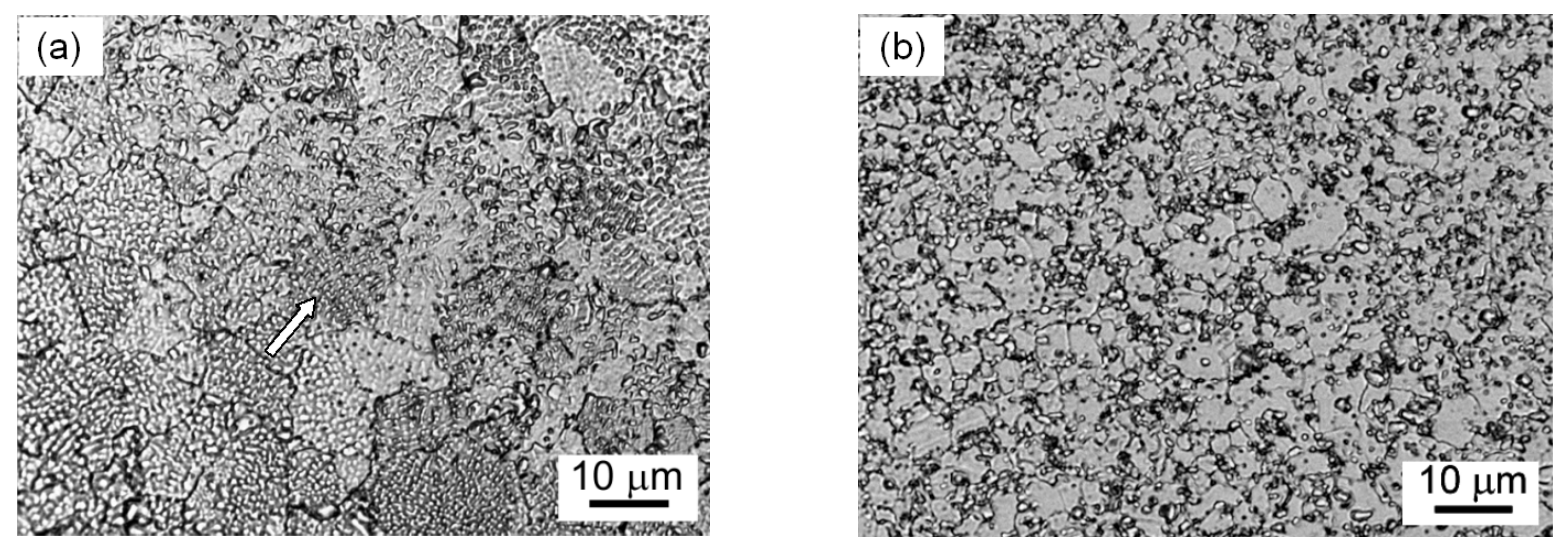

Fig. 1 The grain structures of as-HIPed (a) and as-extruded materials (b)

\section{Compression test stress-strain curves}

The true stress $(\sigma)$-strain $(\varepsilon)$ curves for two test materials are shown in the Fig.2. For the as-HIPed material, all the curves indicate the typical characteristic of dynamic recrystallization, except under the slowest strain rate condition $\left(0.0003 \mathrm{~s}^{-1}\right)$ at $1100^{\circ} \mathrm{C}$. The flow stress rapidly reaches its maximum value (peak flow stress, $\sigma_{\mathrm{p}}$ ) in the early stages of deformation, and then decreases with increasing strain, subsequently, turns into the steady state flow stages with the further increasing of strain, which is more evident for the lower temperatures and higher strain rates. However, the flow stress for as-extruded material appears independent of strain after it reaches $\sigma_{\mathrm{p}}$ with increasing strain at all test conditions, except at the highest strain rate $\left(0.03 \mathrm{~s}^{-1}\right)$ at $1050{ }^{\circ} \mathrm{C}$, which suggests that it would reach the balance between the work hardening and softening due to dynamic recrystallization.

Fig. 3 shows the relationship between $\sigma_{\mathrm{p}}$ and both deformation temperature and strain rate for the two tested materials. For both materials, under the constant strain rate, $\sigma_{\mathrm{p}}$ decreases with increasing temperature, and under a given deformation temperature, $\sigma_{\mathrm{p}}$ increases with increasing strain rate, which suggests that flow stress of both materials show a positive strain rate sensitivity. At the high 

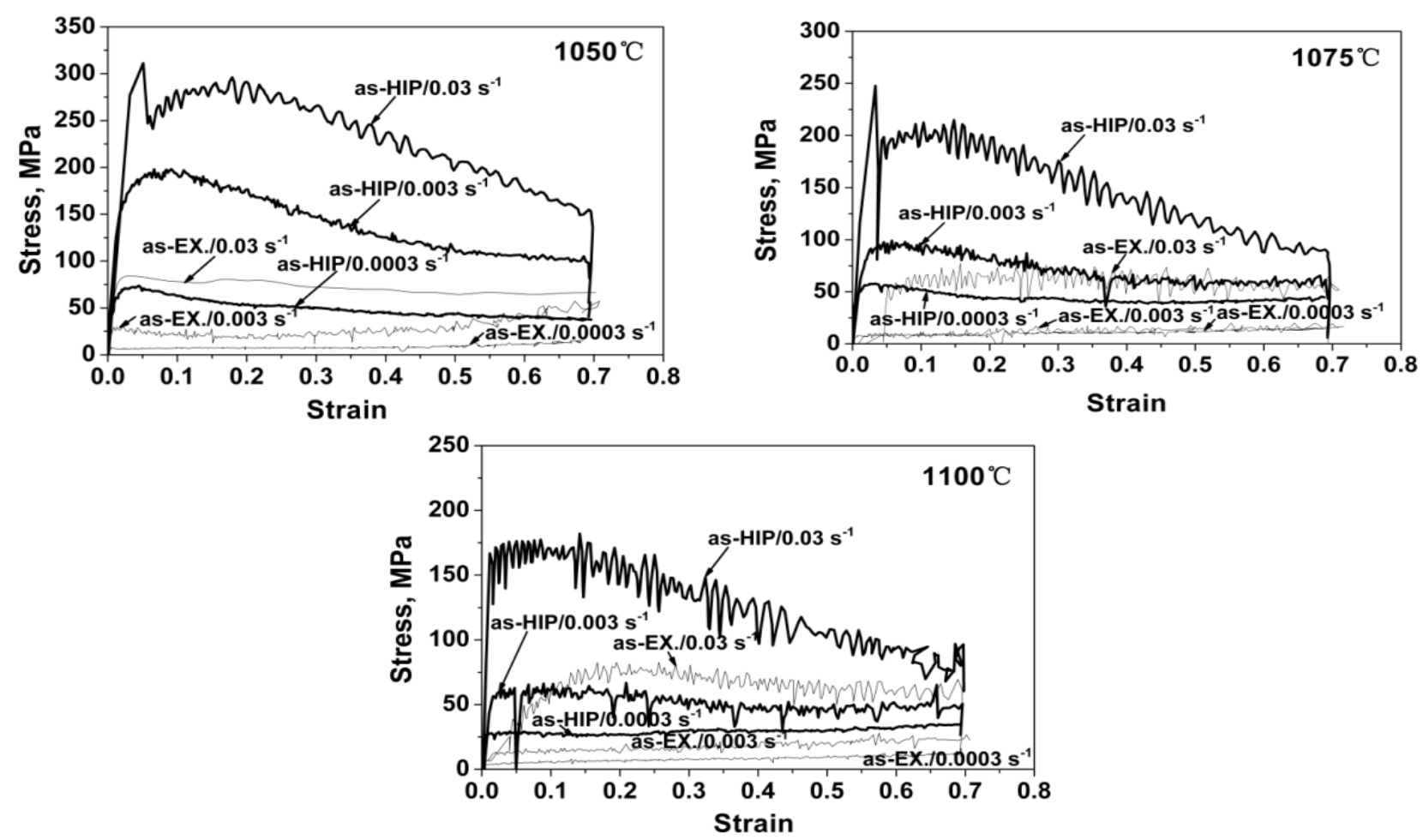

Fig.2 Flow stress curves for two test materials at different temperature and strain rate
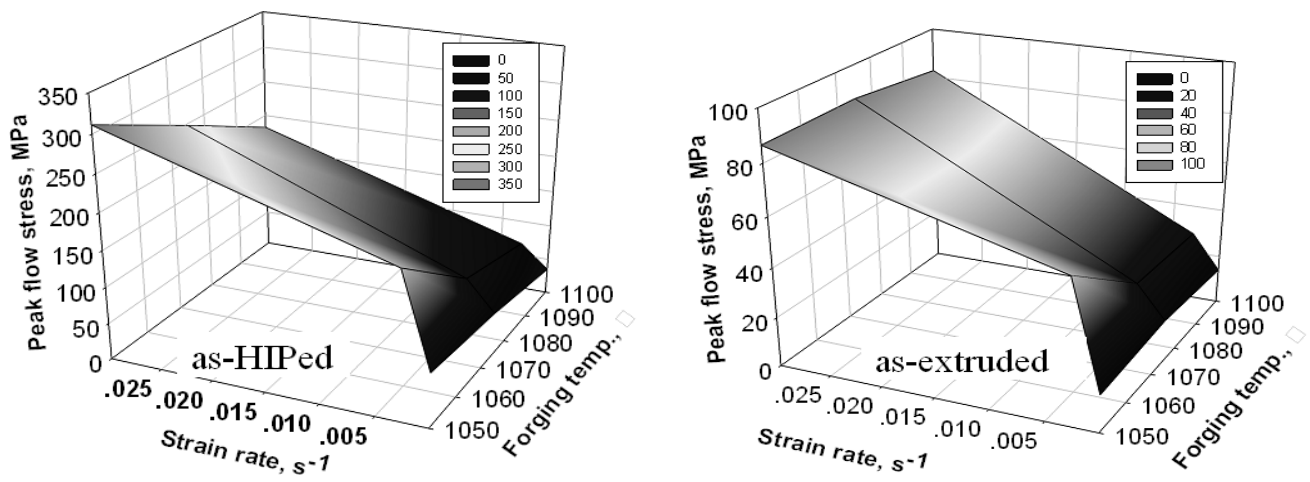

Fig. 3 Relationship peak flow stress vs deformation temperature $\left({ }^{\circ} \mathrm{C}\right)$ and strain rate

strain rates, dislocation density increases rapidly, shortening the dynamic recrystallization or dynamic recovery process, increasing the amount of elasticity deformation, and therefore, resulting in the increase of the critical shear stress of deformation.

It was also found that, under same deformation conditions, the as-extruded material has a smaller flow stress value than the as-HIPed material, which is considered to be associated with the initial microstructure before compression tests; so the as-extruded material is obviously favorable for hot deformation.

\section{Superplastic deformation characteristic}

Strain rate sensitivity $(m)$ can be determined by fitting the linear equation (1) at constant temperature. A material is considered superplastic during plastic deformation when $m$ is higher than 0.3 .

$$
\log (\sigma)=\log K+m \log (d \varepsilon / d t)
$$

The resulting plot and equations for both materials are shown in Fig. 4 (flow stress at a true strain of 0.5 was employed for regression analyses). 

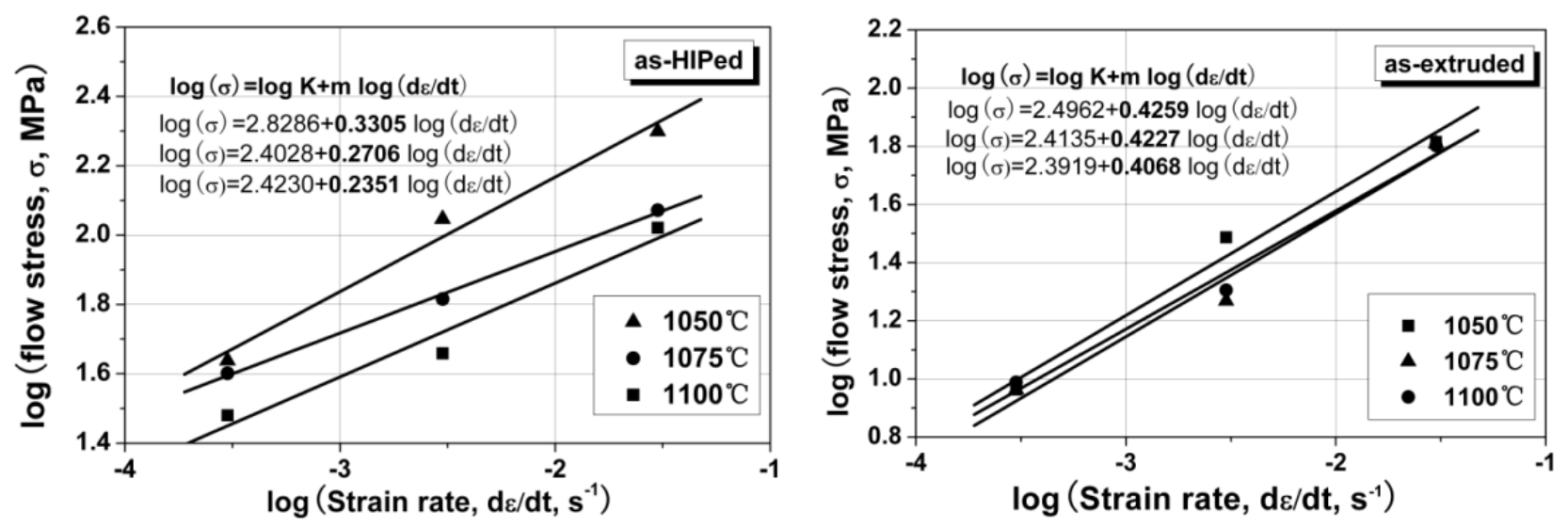

Fig. $4 \log$ (flow stress) vs. $\log$ (strain rate) plots with superplasticity $(m)$ determinations

The strain rate sensitivity $m$ was defined by the slope of each line. The sensitivity for the as-extruded material is above 0.4 at all test conditions. As for the as-HIPed material, however, the values of $m$ are lower than 0.3 except at $1050^{\circ} \mathrm{C}$. Moreover, under same deformation conditions, the as-extruded material has the higher $m$ value than that of as-HIPed material. Therefore the as-extruded material exhibited superplastic flow for the evaluated conditions.

\section{Analysis of the constitutive model}

For the range of deformation conditions employed in this study, flow stress as a function of both deformation temperature and strain rate is analyzed using a hyperbolic sine Arrhenius-type equation $[11,12]$, which is expressed as follows:

$$
\dot{\varepsilon}=A[\sinh (\alpha \sigma)]^{n} \cdot \exp [-Q / R T]
$$

with $A$, a structure factor, $\alpha$, a stress level parameter, $n$, a stress index (materials constants), $\dot{\varepsilon}$, the strain rate, $Q$, the activation energy, $T$, the deformation temperature, $\sigma$, the flow stress, $R$, the universal gas constant $(8.314 \mathrm{~J} / \mathrm{mol} . \mathrm{K})$. The equation (2) can be rearranged to the following form:

$$
\ln \sinh (\alpha \sigma)=-\frac{1}{n} \ln A+\frac{1}{n} \ln \dot{\varepsilon}+\frac{1}{n} \frac{Q}{R T}
$$

After the $\sigma_{\mathrm{p}}-\dot{\varepsilon}$ and $\sigma_{\mathrm{p}}-T$ relationships for the two materials have been obtained, the optimum value of $n$ and the mean value of the activation energy can be determined including the constants, which is summarized in Table 1.

Table 1 Model parameter for the two materials

\begin{tabular}{ccccc}
\hline & $\alpha\left[\mathrm{MPa}^{-1}\right]$ & $\mathrm{A}\left[\mathrm{s}^{-1}\right]$ & $n$ & $\mathrm{Q}[\mathrm{kJ} / \mathrm{mol}]$ \\
\hline as-HIPed & 0.00782 & $1.4667 \times 10^{25}$ & 2.1804 & 717.43 \\
as-extruded & 0.02365 & $3.7024 \times 10^{5}$ & 1.9010 & 210.98 \\
\hline
\end{tabular}

The effect of deformation temperature and strain rate on the flow stress can be expressed by the Zener-Hollomon parameter $Z, Z=\dot{\varepsilon} \exp (Q / R T)$ for different strain rates and temperatures. The relationship between the flow stress and the $\mathrm{Z}$ parameter is shown in Fig. 5 . 


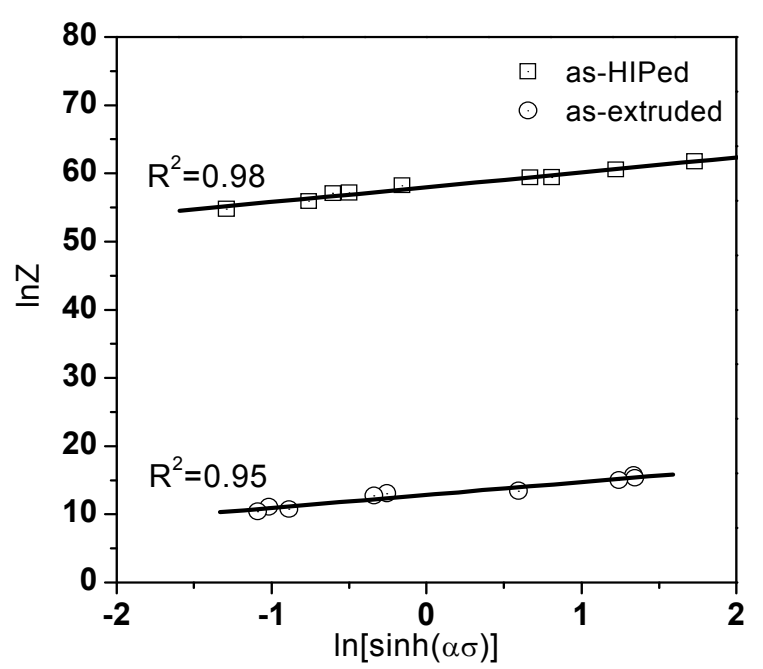

Fig. 5 Relationship between flow stress and the $Z$ parameter

The $n$ value was defined by the slope of the regression line. The linear regression equations indicated that the flow stress increased with increasing $\mathrm{Z}$ parameter with a correlation coefficient $\mathrm{R}^{2}=0.98$ and 0.95 , RMS error $=0.3786$ and 0.4688 for the as-HIPed and as-extruded material, respectively, which suggests that $\ln Z-\ln [\sinh (\alpha \sigma)]$ has the ideal linear relationship. The experimental flow stress can be represented by a Zener-Hollomon parameter in the hyperbolic Arrhenius-type equation.

Thus the constitutive models for both tested materials can be expressed respectively as equation (4) and (5):

$$
\begin{array}{ll}
\text { as-HIPed } & : \dot{\varepsilon}=1.4667 \times 10^{25}[\sinh (\varepsilon \sigma)]^{2.1804} \cdot \exp [-717.43 / R T] \\
\text { as-extruded } & : \dot{\varepsilon}=3.7024 \times 10^{5}[\sinh (\varepsilon \sigma)]^{1.9010} \cdot \exp [-210.98 / R T]
\end{array}
$$

\section{Effect of deformation parameter on the microstructure}

Microstructures for both as-HIPed and as-extruded materials deformed at the different temperatures and strain rates were observed for comparison. The micrographs reveal that the deformed microstructure is affected by the deformation conditions, and the recrystallized regions and the grain size increase with increasing deformation temperature and decreasing strain rate. The as-cast dendritic structure left in the as-HIPed material (Fig. 1a) is still observed at most test conditions, and it is entirely eliminated at $1100^{\circ} \mathrm{C}$ (the highest deformation temperature) and $0.03 \mathrm{~s}^{-1}$ (the fastest strain rate). The change of deformed grain size with the deformation temperature and the strain rate for the as-extruded material is similar to that of the as-HIPed material. It was also noted that, under the same deformation condition, the average grain size for the as-extruded material is always slightly smaller than that of the as-HIPed material, which is considered to be associated with the initial grain size of the materials.

It can be also obtained that although the difference in the deformed microstructure for both materials are not obvious, especially at the highest temperature $\left(1100^{\circ} \mathrm{C}\right)$, the difference in flow stress at a given strain rate can be quite significant. This phenomenon indicates that there is a strong dynamic flow during deformation process, the as-extruded material exhibits the more lower flow stress due to the contribution of grain boundary sliding mechanisms. The sufficient fine grain size confers superplastic characteristics on the as-extruded material. The sufficient fine grain size confers superplastic characteristics to the as-extruded material. 
Extrusion was widely used to obtain the excellent microstructure of pre-forgings. The full recrystallized fine-grained structure can be obtained after extrusion, which enhances the deformation properties of materials. The main deformation model for the new alloy is the dislocation movement during extrusion process, associated with the formation of abundant twins, both of which are influenced and coordinated by each other. Ultimately, the equiaxed, uniform fine-grain structure was formed as a result of dynamic recrystallization.

\section{Conclusions}

This paper shows that the microstructure of as-HIPed and as-extruded materials can be changed substantially during hot deformation, and is influenced by the applied strain rate and temperature. The grain size for the two materials decreased with increasing strain rate and decreasing deformation temperature. Under most test conditions, grain growth occurs during deformation for the as-extruded material corresponding to the work hardening, exhibiting superplastic flow, the activation energy of which is $211 \mathrm{~kJ} / \mathrm{mol}$. However, grain size is refined for the as-HIPed material due to dynamic recrystallization, the activation energy of which is $717 \mathrm{~kJ} / \mathrm{mol}$. Based on the experimental results and analysis, two equations for both materials are established to describe the relationship between flow stress, deformation temperature and strain rate.

\section{References}

[1] G. Raisson: Powder Metall., 50 (2008), p. 10

[2] J.C. Williams and E.A. Starke: Acta Mater. 51 (2003), p. 5775

[3] J.C. Zhao and J.H. Westbrook: MRS Bulletin 28(9) (2003), p. 622

[4] T.P. Gabb, D.L. Ellis, M. Kenneth, et al. :NASA/TM - 2004-213066, Cleveland, 2004

[5] T. T.P. Gabb, J. Gayda and J. Falsey: NASA/TM - 2005-213649, Cleveland, 2005

[6] J. Gayda: NASA/TM - 2000-210358, Cleveland, 2000

[7] J.Y. Guédou, I. Augustins-Lecallier, L. Nazé et al. In: R.C. Reed, P. Caron, eds., Proceeding of the $11^{\text {th }}$ International Symposium on Superalloys, Superalloy 2008, TMS, Warrendale, PA, 2008, p. 21

[8] S.L. Semiatin, P.N. Fagin, M.G. Glavicic, et al.: Scripta Mater. 50 (2004), p. 625

[9] A. Nowotnik: J. Achi. Mater. Manufacturing Eng. 27(2008), p. 115

[10] S. Kikuchi, S. Ando, S. Futami, et al.: J. Mater. Sci. 25 (1990), p. 4712

[11] R. Sandstörm and R. Lagneborg: Acta Metall. 23 (1975), p. 481

[12] K.P. Rao and E.B. Hawbolt: Transactions of ASME, J. Eng. Mater. Tech., 114 (1992), p. 116 